\title{
FINANCEIRIZAÇÃO E INTERNACIONALIZAÇÃO NO SETOR DE SERVIÇOS \\ DE SAÚDE: IMPACTOS SOBRE O BRASIL
}

\author{
Celio Hiratuka \\ Marco Antonio Rocha \\ Fernando Sarti
}

Area Temática: Area 2

JEL: F23; G34

Palavras Chave: Internacionalização, Financeirização, Serviços de Saúde

\section{INTRODUÇÃO}

Este artigo tem como objetivo analisar o movimento de internacionalização do setor de serviços de saúde em nível internacional, com destaque para o movimento de fusões e aquisições e avaliar os impactos desse processo sobre a economia brasileira.

Para isso, na seção 1, realiza-se uma breve revisão sobre o movimento de internacionalização e financeirização das empresas não financeiras. Essa análise é seguida pela descrição das estratégias de internacionalização dos grandes grupos de serviços de saúde na seção 2. Associam-se essas estratégias tanto à capitalização de grandes fundos de investimento, quanto à necessidade de buscar novos mercados para fazer frente à elevação de custos de atendimento. Em seguida, na seção 3, são analisados os impactos deste movimento sobre o Brasil e a forma como ele está relacionado ao movimento de aquisições de atores empresariais importantes por grupos internacionais no período recente. Finalmente a última seção apresenta as considerações finais.

\section{INTERNACIONALIZAÇÃO E FINANCEIRIZAÇÃO NO PERÍODO RECENTE}

A economia mundial vem passando por um profundo processo de internacionalização nos últimos anos. Embora o aumento das transações econômicas internacionais não seja recente, a forma como ela ocorreu no chamado processo de globalização, trouxe novidades importantes.

Em primeiro lugar deve-se destacar a velocidade do processo. Observou-se um cenário onde o movimento de internacionalização se aprofundou enormemente, ao mesmo tempo em que o mapa da produção, do comércio, dos investimentos, das finanças e do conhecimento tecnológico também passou por transformações profundas. Além da 
velocidade no processo de internacionalização, também deve ser destacado as transformações na forma de concorrência.

Desde a década de 80, a gestão e a forma de operação internacional das grandes corporações vem se transformando de maneira profunda, resultado em grande parte das estratégias das corporações americanas, pressionadas pela competição acirrada levada a cabo por empresas da Europa Continental e do Japão. De outro lado, a grande empresa americana encontrou-se pressionada também pelo crescente questionamento acerca da eficiência do modelo gerencial da grande corporação multidivisional diversificada. Para os críticos desse modelo, a autonomia exagerada dos gerentes para alocar os lucros acumulados havia criado corporações excessivamente diversificadas, com a implementação de projetos de investimentos que não necessariamente geravam retornos aos acionistas (Jensen, 1989).

Acionistas mais ativos, remunerações atreladas ao desempenho das ações e o movimento de fusões e aquisições hostis seriam as formas de disciplinar e implementar um novo modelo de gestão, mais alinhado com o interesse dos acionistas, nessas grandes corporações. De acordo com Lazonick e O’Sullivan, (2000) a consolidação de uma nova forma de governança corporativa, fundada no princípio de maximizar o valor para o acionista teria alterado profundamente a forma de organização da grande empresa americana, que de um modelo baseado nos princípios de "reter e reinvestir" passou a ser guiada pelos princípios de "reduzir e distribuir"1. De uma situação onde a gestão tinha autonomia para gerenciar os fluxos de caixa acumulados para canalizar investimentos para manter expandir os ativos tangíveis e intangíveis (incluindo as capacitações acumuladas pelos trabalhadores nos vários níveis da estrutura organizacional) e os acionistas eram majoritariamente famílias que investiam com um horizonte de longo prazo, passou-se a uma nova lógica, onde a firma deveria evitar manter lucros acumulados que não encontrassem os retornos ajustados ao risco exigidos pelos acionistas. Esses acionistas, por sua vez deixaram de ser compostos majoritariamente por famílias e passaram a ser constituídos por fundos de investidores institucionais, que pressionavam por ajustes em direção a uma estrutura mais flexível, menos comprometida com custos fixos, e por maior acesso ao fluxo de caixa acumulado, seja sobre a forma de dividendos, seja sob a forma de recompra de ações.

Crotty (2002) apresenta uma visão similar à de Lazonick e O’Sullivan (2000), conforme explicita a citação a seguir:

"I stress two key dimensions of the changing relation of financial markets to large Non-Financial Corporations (NFC) in the neoliberal era. The first is a shift in the beliefs and behavior of financial agents, from an implicit acceptance of the Chandlerian view of the large NFC as an integrated, coherent combination of relatively illiquid real assets assembled to pursue long-term growth and innovation, to a "financial" conception in which the NFC is seen as a 'portfolio' of liquid subunits that home-office management must continually restructure to maximize the stock price at every point in time. The second is a fundamental change in the incentives that guide the decisions of top managers, from one that linked long-term managerial pay to the long-term success of the firm, to one that links their pay to short-term stock price movements. This created an alignment of the interests of

\footnotetext{
${ }^{1}$ No original "Retain and Reinvest" e "Dowsizing and Distribute". Lazonick e O'Sullivan (2000)
} 
management with those of institutional financial investors and wealthy households and against the interests of other firm stakeholders. Both changes drastically shortened the planning horizons in large NFCs and led management to adopt strategies that undermined general economic performance.”

Neste contexto, o sentido geral do movimento de reestruturação empresarial buscou aliar a acumulação de ativos intangíveis com movimentos racionalização e busca por flexibilidade, de maneira a responder ao mesmo tempo à pressão competitiva, à maior instabilidade das variáveis macroeconômicas e às exigências de retorno mais elevado e rápido derivados da crescente pressão do mercado financeiro sobre a gestão corporativa. Além disso, é importante destacar que o reconhecimento das mudanças na gestão das grandes corporações e de seus impactos sobre a dinâmica econômica e a distribuição de renda tem sido objeto de crescente atenção nos anos recentes, mobilização de estudiosos de diferentes áreas (economia, sociologia, ciência política e geografia entre outros), que buscam tratar o tema da financeirização sob diferentes ângulos (Epstein, 2005, Van Der Zwan (2014).

Quando se trata de analisar os impactos do movimento de financeirização sobre os países em desenvolvimento, a maior parte das abordagens ressalta os impactos macroeconômicos negativos associados à liberalização financeira e à volatilidade dos fluxos de capital. Do ponto de vista dos impactos sobre a estrutura produtiva autores como Milberg e Winkler (2009) e Serfati (2008) destacam como o novo contexto gerou impactos importantes sobre a organização internacional da produção, sobre a formação das cadeias globais de valor e sobre o domínio dos ativos tecnológicos. A maior internacionalização, aliada à terceirização internacional de parcela crescente das etapas produtivas passou a ser uma estratégia importante resultando em uma grande descentralização das atividades produtivasA elevação do poder de comando das grandes corporações dos países centrais sobre o valor gerado nas diferentes regiões foi potencializado e o aumento do escopo global passou a ser um fator fundamental na luta competitiva, resultado das vantagens associadas à capacidade de diversificar riscos, operar em vários mercados, explorar diferenciais de custos e vantagens de localização em diferentes regiões.

Um aspecto pouco ressaltado na discussão diz respeito à forma como a própria expansão internacional está em grande medida associada a movimentos intensos de acirramento de disputas concorrenciais via fusões e aquisições, alavancados por grandes fundos financeiros. Neste sentido, entende-se que este texto pode indicar evidências da importância deste processo.

Como pode ser visto através do gráfico 1, os valores das fusões e aquisições internacionais também apresentaram uma tendência clara de elevação desde os anos 90, apesar das intensas flutuações ocorridas, seguindo o mesmo movimento observado nos fluxos de IDE. Depois de atingir um recorde de transações em 2007, quando atingiu mais de US\$ 1 trilhão, o movimento anual passou a oscilar em torno dos US\$ 400 bilhões anuais. A interpenetração entre os fluxos financeiros e os ativos reais também pode ser analisada por estes dados, uma vez que a elevada liquidez internacional e a hipertrofia das transações financeiras resultaram em uma disponibilização ampla de recursos para alavancar a compra de ativos no mercado mundial, reforçando o processo de concentração e centralização do capital em nível global. 
No caso específico do setor de serviços, o processo de especialização vertical ocorrido na indústria e a terceirização de algumas atividades também permitiu liberar o processo concorrencial para empresas se especializarem nestas atividades. Em muitos casos, a desverticalização de algumas atividades possibilitou a ampliação das escalas produtivas e a concentração do mercado de atividades de serviços, sobretudo nos setores ligados ao suporte de atividades industriais. Este processo abriu espaço para formação de um conjunto de grandes empresas prestadoras de serviços operando em escala global.

Separando as transações por grupo de atividade envolvida nas operações de fusões e aquisições, é possível perceber que a atividade de serviços representou grande parcela deste movimento. Mesmo separando os serviços financeiros, que responderam na maior parte dos anos pela maior parte do valor transacionado, os valores das fusões e aquisições são bastante significativos.

\section{Gráfico 1 - Valor das Fusões e Aquisições Internacionais (Compras) por atividade . Em US\$ bilhões. 1990 a 2012.}

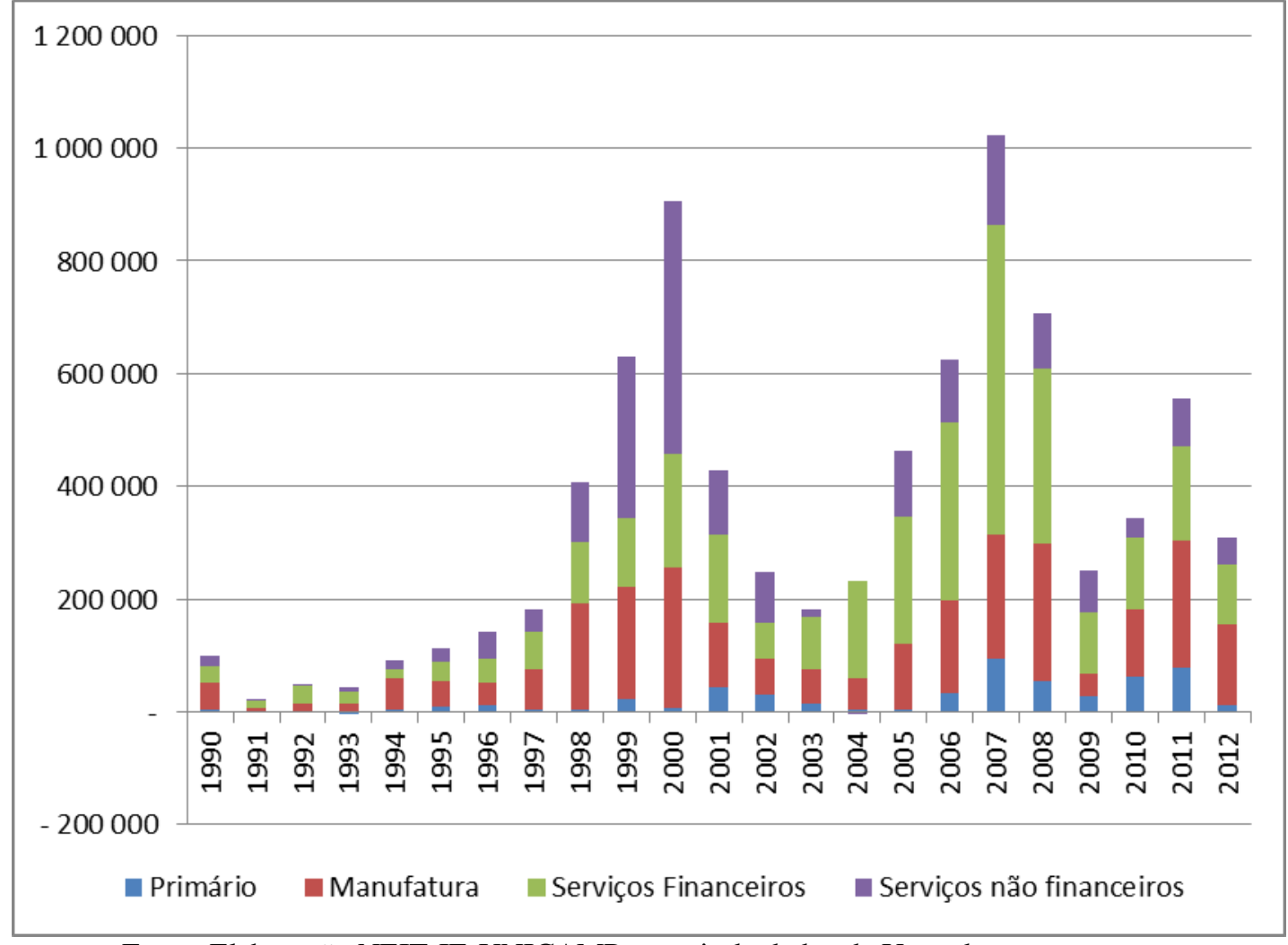

Fonte: Elaboração NEIT-IE-UNICAMP a partir de dados da Unctad.

Como destacado pela UNCTAD (2004), o aumento dos investimentos direto e das fusões e aquisições no setor de serviços foram impulsionados tanto pelos processos de privatizações de setores como telecomunicações e de energia, quanto pela liberalização ocorrida em vários países, abrindo espaço para o capital estrangeiro em vários segmentos onde a regulamentação impedia a participação de capital externo. Também é importante destacar a diversificação dentro do segmento de serviços, englobando além dos setores já citados, os segmentos de transporte, hotelaria e alimentação, e, mais recentemente, 
atingindo setores que tinham sido menos atingidos pela internacionalização, como educação e saúde.

Estes aspectos chamam atenção para a crescente internacionalização observada na economia mundial, acompanhada ao mesmo tempo de um movimento intenso de reestruturação patrimonial com um processo expressivo de fusões e aquisições, resultando em um grau de centralização de capital sem precedentes em vários setores e atividades. Se em um primeiro momento, as atividades industriais sofreram de maneira mais intensa esse processo, mais recentemente os setores de serviços têm sido afetados também. Em primeiro momento, os setores de energia e telecomunicações foram os vetores desse movimento. Mais recentemente esse movimento tem se expandido para outros setores, mais diretamente relacionados com a oferta de serviços básicos à população, e portanto, também mais sujeitos à regulação estatal, como educação e saúde.

No caso do setor de serviços de saúde, o caso é relevante devido não só ao acirramento das estratégias de redução de custos, mas também à forma como estas empresas estão inseridas no processo de desenvolvimento tecnológico das atividades ligadas à área médica, como será discutida na seção seguinte. A ótica de valorização de curto prazo e as alterações repentinas as quais as estruturas de propriedade com grande participação de fundos financeiros estão sujeitas, afetam não só a forma de prestação de serviço para a população como também podem ter efeitos importantes sobre a continuidade de pesquisas e testes de novas tecnologias.

\section{SERVIÇOS DE SAÚDE: CARACTERIZAÇÃO INTERNACIONAL E EMPRESAS LÍDERES}

\subsection{Caracterização Geral}

Há uma série de fatores que torna a saúde, do ponto de vista da organização econômica, um setor repleto de particularidades, de difícil enquadramento nas normas convencionais de regulação dos mercados. Em outros termos, poucas características do setor de saúde justificariam deixar sua regulação a mercê meramente das leis de mercado. Estes fatores vão desde uma estrutura peculiar de demanda e oferta, a forma como este setor se insere no desenvolvimento de tecnologias de saúde, passando pela forma pela qual o risco e a assimetria de informação afetam a organização do setor. Esses fatores fornecem, por vezes, uma dinâmica de concorrência com forte caráter concentrador, sendo que, em se tratando de saúde, a criação de poder de mercado frente ao consumidor é particularmente mais preocupante do que o usual em outros mercados.

Dentro do macrosetor de saúde, as empresas prestadoras de serviços de saúde também se inserem nesta dinâmica. No segmento incluem-se empresas de saúde coletiva, tais como seguradoras e cooperativas de saúde, laboratórios de análises clínicas e serviços radiológicos, empresas administradoras e proprietárias de hospitais e clínicas e empresas de logística de saúde - como fornecedoras de insumos médicos e prestadoras de serviços de remoção. Compondo parte do macrosetor de saúde, este conjunto de empresas compartilham algumas características gerais que definem a saúde enquanto um setor econômico; por outro lado, por não estarem ligadas diretamente a produção, como as 
farmacêuticas ou empresas de equipamentos médicos, as prestadoras de serviços possuem uma lógica de concorrência própria, pautada por alguns aspectos bem específico ao seu conjunto de atividades.

A primeira questão de ordem geral diz respeito ao fato de ser simultaneamente responsável pelo fornecimento de algo que é reconhecido em muitos casos como um direito, compondo parte dos direitos de cidadania e visando a universalidade de acesso, e também ser a saúde uma "mercadoria altamente geradora de valor" (Conill, 2008). Do reconhecimento desse problema, deve-se em boa parte a organização dos sistemas nacionais de saúde, cuja organização afeta diretamente a lógica de atuação das empresas privadas.

Destaca-se ainda, o fato do fornecimento de serviços de saúde ser uma atividade altamente geradora de externalidades positivas para o sistema econômico como um todo. Sendo que, neste sentido, o fornecimento de serviços em todos os níveis, e principalmente em atenção básica, contribui para a maior eficiência do funcionamento do sistema econômico, justificando a atuação da esfera pública na regulamentação e complementação da oferta de serviços.

A organização dos sistemas nacionais de saúde define em formas gerais a divisão de trabalho entre a esfera pública e privada, assim como a estrutura de financiamento e as formas de remuneração das empresas privadas de serviços de saúde. As modificações nos sistemas de saúde portanto afetam os padrões de concorrência do setor de saúde e este fenômeno pode ser facilmente percebido a partir das ondas de fusão, aquisições e mudanças nas estratégias das grandes empresas que se seguem às mudanças nas legislações que regulam os sistemas públicos de saúde. Além disto, o setor caracteriza-se geralmente também pela existência de empresas não lucrativas, como instituições religiosas e de caridade ou ligadas a grupos étnicos específicos.

No que tange a estrutura de demanda dos serviços de saúde, algumas características são particularmente importantes para compreender a relação entre usuários dos sistemas de saúde e empresas. Do ponto de vista do usuário, a demanda por serviços de saúde é marcada por uma forte assimetria de informação, entre o usuário e o especialista que prescreve o serviço, impondo ao serviço demandado um caráter de "necessidade", sendo caracterizada pela baixa elasticidade-preço e sobretudo pela imprevisibilidade dessa demanda (Iunes, 1995). Dada também a incerteza a respeito da utilização e custos destes serviços, é normal a interposição de agentes administradores do risco, como seguradoras, que por geralmente estarem associadas a uma rede específica de fornecedoras de serviços tendem a restringir a livre substituição entre ofertantes.

A visão de que o fornecimento de serviços de saúde é marcado principalmente por imperfeições de mercado, que o afasta do que seria o funcionamento adequado de um mercado segundo a teoria convencional, faz parte das contribuições do artigo seminal de Kenneth Arrow sobre o tema (Arrow, 1963). Segundo o autor, as imperfeições afetariam não só a estrutura de demanda como também a estrutura de oferta do setor. Primeiramente, em relação à capacidade das empresas discriminarem preço em relação às faixas de renda e realizarem cobranças diferenciadas - como taxas extras vinculadas a utilização de certos serviços - o que associada a uma baixa elasticidade-preço possibilita às empresas, como ensina qualquer manual convencional de microeconomia, uma grande capacidade de se 
apropriarem do excedente do consumidor. Outro aspecto é a importância que a informação sobre o histórico dos pacientes e aplicação de métodos de tratamento e diagnóstico possui na composição dos custos e na formação dos preços, o que contribui para gerar vantagens competitivas para formas mais concentradas de comando, tais como empresas verticalizadas ou associações entre empresas.

No que se refere à assimilação de tecnologias por parte das empresas de serviços de saúde, embora estas não sejam geralmente produtoras de novas tecnologias, eles possuem uma posição importante na disseminação tecnológica de novos métodos e produtos. Por concentrarem a oferta de serviços de saúde, as empresas se estabelecem como interfaces entre o usuário final e as empresas inovadoras, definindo as condições de utilização e o ritmo da adoção de novas tecnologias. As empresas de serviços de saúde são responsáveis por boa parte do fornecimento das informações necessárias às mudanças incrementais, adaptações e ajustes para a utilização de novas tecnologias, ou seja, são geralmente o lócus do processo de "learning by using” das tecnologias médicas.

Em muitos casos, as pesquisas são realizadas dentro das próprias empresas de serviço - como no caso dos hospitais e clínicas - sendo que não necessariamente com participação destas nos resultados e no financiamento. Mesmo assim, a cooperação das empresas para a geração de certa estabilidade e continuidade das condições de pesquisa são fundamentais para o avanço tecnológico nesta área. Logo, percebe-se a importância da estabilidade de algumas estruturas de propriedade do setor como forma de garantir a continuidade no longo prazo das pesquisas e o feedback dos resultados de novas tecnologias.

Da perspectiva das empresas de serviços de saúde, a adoção de novas tecnologias também significam em muitos casos custos fixos crescentes. Dada a capacidade de discriminação de preços e de cobranças diferenciadas por serviços, a adoção de novas tecnologias também constituiu um fator de competitividade e de aumento da rentabilidade via diferenciação da oferta de serviços, o que induz um ritmo acelerado na adoção de inovações e, simultaneamente, forte pressão competitiva no sentido da ampliação da escala de operação. Este movimento acaba gerando um viés concentrador na disputa pelos mercados, sobretudo em relação aos novos mercados em expansão.

Deste modo, a dinâmica concorrencial fica sujeita a uma tendência constante de aumento da importância das economias de escala enquanto as mudanças na organização dos sistemas públicos de saúde podem atuar ampliando ou reduzindo o espaço de atuação das empresas, impondo também limites a práticas discriminatórias de preços e a certas condutas estratégicas das empresas líderes. Estes conflitos podem reduzir o mercado das empresas levando a adoção de estratégias de diversificação e internacionalização mais ou menos acirradas.

Este cenário foi particularmente o que se apresentou nos anos recentes, caracterizados por um conjunto de mudanças na organização dos sistemas públicos de saúde nos países centrais. Estas mudanças levaram as empresas a buscar ampliar seus espaços de atuação e suas escalas de operação, internacionalizando e verticalizando suas atividades, levando a mais uma onda de fusões e aquisições nos países centrais. Tem 
contribuído crescentemente para a velocidade deste processo o aporte de capital provenientes de diversos fundos financeiros, que têm procurado adquirir participação em grandes empresas de serviços de saúde ou a formação de joint ventures para o processo de crescimento de alguma delas (Patterson, 2013).

Como pode ser visto no Gráfico 2, As operações totais de fusões e aquisições realizadas globalmente vem tendo uma tendência clara de aumento desde o início dos anos 2000. O número de operações registrado foi de 39 em 1999, crescendo rapidamente a partir de então, até chegar a 415 operações em 2008. A crise internacional fez com que ocorresse uma queda em 2009, porém o crescimento volta a acontecer a partir de 2010. Em 2012 houve o recorde de 432 operações, seguido por pequena queda em 2013. Em termos de valor $^{2}$, a ocorrência de algumas operações com valor elevado torna a série mais volátil, com picos em 2003 e 2004, quando foram atingidos valores superiores a US\$ 30 bilhões. No entanto, mesmo com a redução ocorrida posteriormente, o patamar das operações globais permanece entre U\$ 10 e 15 bilhões por ano.

\section{Gráfico 2 - Fusões e Aquisições no setor de serviços de saúde. 1997 a 2013. Em} número de operações e valor

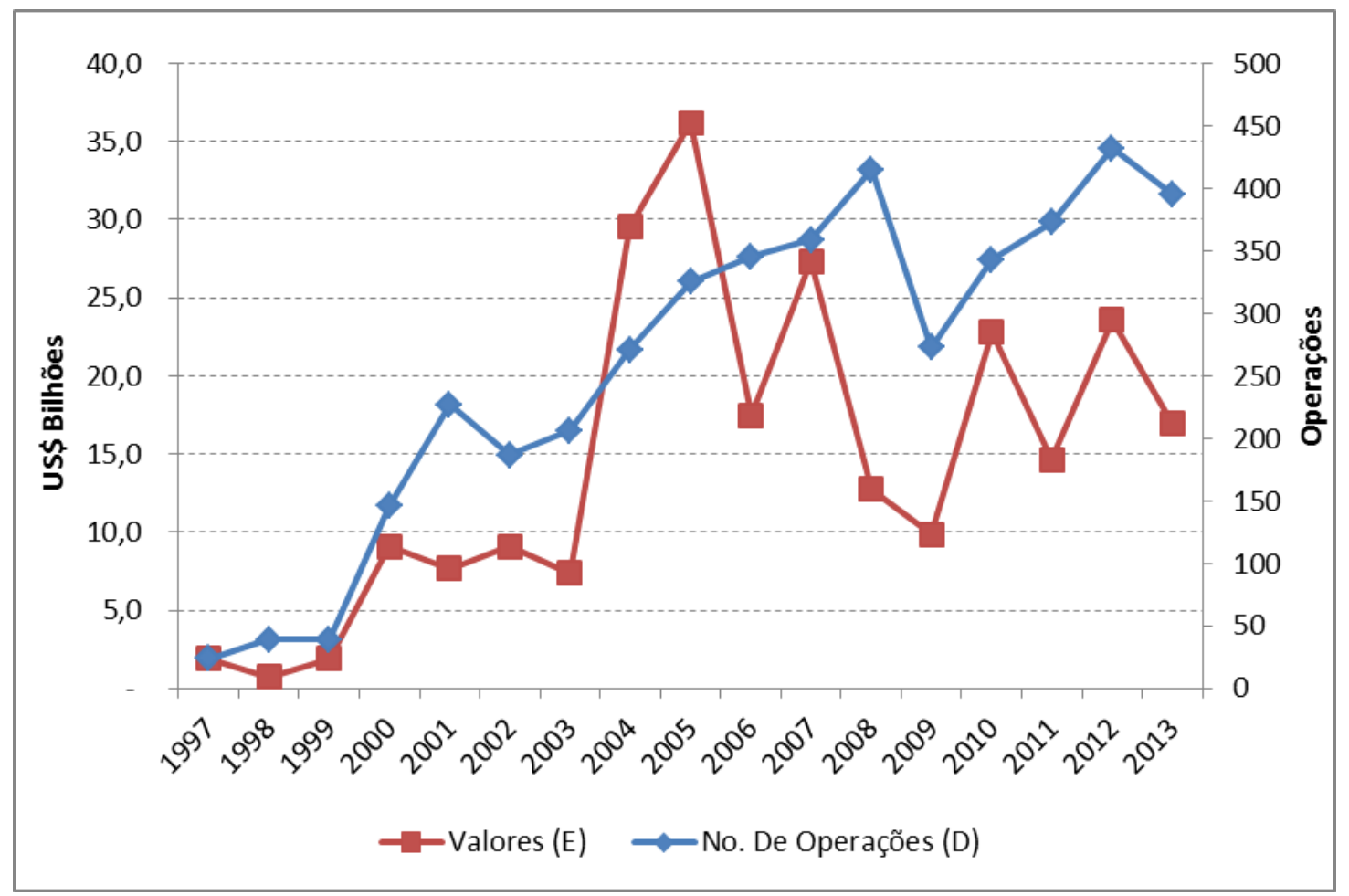

Fonte: Elaboração NEIT/IE/UNICAMP a partir de dados de Zephir/BVD.

Este fenômeno tem acelerado o ritmo de concentração do mercado e contribuído para o crescimento do porte das principais empresas globais. $\mathrm{O}$ aumento da renda dos países em desenvolvimento, resultando no surgimento de uma ampla gama de novos

\footnotetext{
${ }^{2}$ Nem todas as operações têm informações de valor registradas. O valor das operações corresponde apenas à soma das operações com valor registrado.
} 
consumidores, permitiu a este processo ganhar fôlego, e acirrar a corrida à aquisição de ativos estratégicos para o aproveitamento destes mercados.

Considerando apenas os processos de fusões e aquisições internacionais, isto é, quando as empresas adquirentes e adquiridas são de países diferentes, observa-se também uma elevação ao longo dos últimos anos (Gráfico 3). O número de operações foi de apenas 5 em 1997, e passou a registrar crescimento acentuado, chegando a 62 operações em 2008. Após a crise observa-se uma desaceleração, porém em 2013 o número de operações atinge novo recorde, com 64 operações registrada. Em termos de valor, os patamares apresentam um crescimento consistente especialmente a partir de 2004, quando, apesar da volatilidade, é possível perceber um volume de transações com valor mais elevado. O ano de 2012 marca o auge dos valores registrado, com US\$ 6,6 bilhões.

Gráfico 3 - Fusões e Aquisições Internacionais no setor de serviços de saúde. 1997 a 2013. Em número de operações e valor

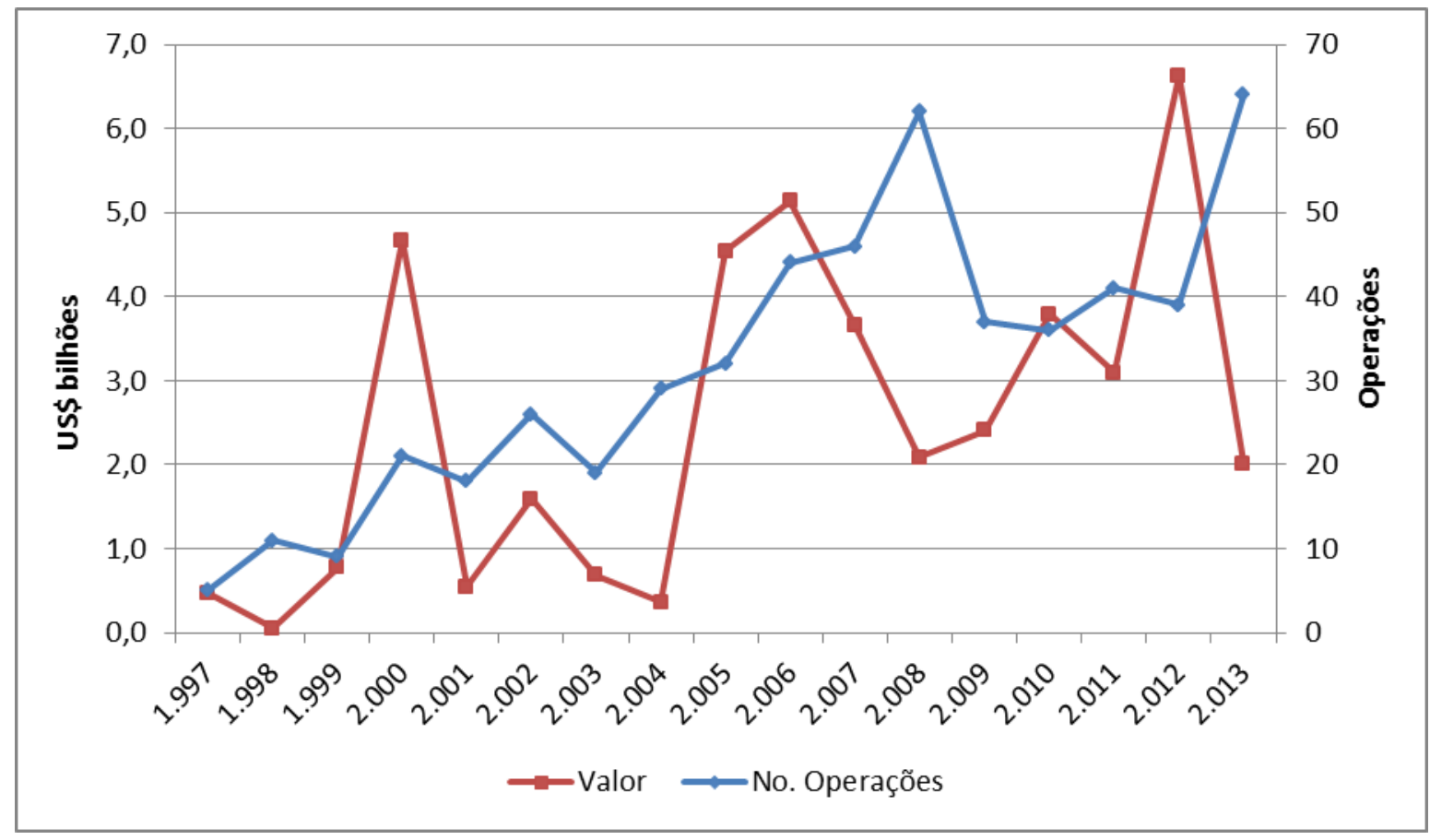

Fonte: Elaboração NEIT/IE/UNICAMP a partir de dados de Zephir/BVD

Deste modo, o movimento de concentração iniciado recentemente nos países centrais vem se espalhando para os países em desenvolvimento, tendo como efeito o aumento da participação de empresas estrangeiras nos sistemas nacionais de saúde destes países. A seção seguinte apresenta as principais características do crescimento das maiores empresas de serviços de saúde operando internacionalmente.

\subsection{Crescimento recente das empresas líderes do setor de Serviços de Saúde}


O impacto da crise econômica sobre os sistemas nacionais de saúde dos países desenvolvidos se fez sentir na reorganização dos gastos sociais a partir da restrição fiscal a que muitos destes países ficaram sujeitos. Ao mesmo tempo em que a própria crise provocava o crescimento do desemprego e da pobreza e exigia destes sistemas uma ampliação dos cuidados necessários à população com renda mais baixa. Os efeitos sobre as empresas dos países desenvolvidos foram bem assimétricos, resultando em alguns casos, como nos Estados Unidos, em um forte movimento de concentração e internacionalização das empresas líderes ${ }^{3}$. Este movimento foi acompanhado do surgimento de novas sociedades entre empresas e fundos financeiros que permitiram a capitalização das estratégias de crescimento, elevando em média o tamanho das empresas envolvidas na disputa internacional dos mercados de serviços de saúde.

As principais empresas de serviços de saúde selecionadas aqui: UnitedHealth, Hospital Corporation of America (HCA), Community Health Systems, Fresenius Medical Care, NetCare, Ramsay Helath Care, Kindred Healthcare, Rhön-Klinikum AG (RHK) e a Capio $A B$, representam um grupo significativo deste processo. Ainda que a presença da família fundadora não seja incomum em algumas empresas de serviços de saúde de grande porte, a composição dos acionistas minoritários caracterizada pela presença de fundos financeiros tornou-se comum. A formação de consórcios de fundos financeiros de grande porte tem sido o principal fator determinante da dinâmica de concentração do mercado internacional.

\begin{tabular}{|c|c|c|c|}
\hline Empresa & origem & $\begin{array}{c}\text { Receita } \\
\text { Operacional }\end{array}$ & Ativos Totais \\
\hline UnitedHealth & EUA & 99,7 & 80,8 \\
\hline$H C A$ & EUA & 18 & 63 \\
\hline $\begin{array}{c}\text { Community } \\
\text { Health }\end{array}$ & EUA & 13 & 16,6 \\
\hline Fresenius $A G$ & Alemanha & 72 & 112 \\
\hline NetCare & Africa do Sul & 7,3 & 16,4 \\
\hline $\begin{array}{c}\text { Ramsay Health } \\
\text { Care }\end{array}$ & Austrália & 4 & 3,7 \\
\hline $\begin{array}{l}\text { Kindred } \\
\text { Healthcare }\end{array}$ & EUA & 4,9 & 4,2 \\
\hline$R H K$ & Alemanha & 4 & 4,2 \\
\hline Capio $A B$ & Suécia & 1,6 & 2 \\
\hline
\end{tabular}

Fonte: Bureau Van Dijk.

\footnotetext{
${ }^{3} \mathrm{O}$ número de fusões e aquisições na área de serviços de saúde mais do que dobrou no período pós-crise nos Estados Unidos - chegando a 105 operações somente no ano de 2012 - criando a segunda maior onda de fusões e aquisições desde a rodada de concentrações ocorridas após a reforma de 1990 de Hillary Clinton.
} 
A UnitedHealth, a maior das empresas analisadas, é emblemática neste sentido. A empresa foi fundada em meados da década de 1970 a partir de uma associação de médicos. A companhia abriu capital em 1984 e iniciou uma série de aquisições no começo dos anos 1990, terminando a década já como um dos principais conglomerados do setor nos Estados Unidos. Seguindo a trajetória de concentração do mercado norte-americano, a UnitedHealth iniciou nos anos 2000 mais uma rodada de aquisições, incluindo algumas grandes empresas. Ao longo da última década a UnitedHealth adquiriu a Pacificare Health Systems por cerca de US\$ 8,7 bilhões, a Oxford Health Plans por US\$ 5 bilhões, a Sierra Services por cerca de US\$ 3 bilhões e a Amil, principal ativo da companhia fora dos Estados Unidos, por aproximadamente US\$ 6 bilhões.

Neste sentido, a participação dos fundos financeiros foi fundamental. A UnitedHealth possui uma estrutura acionária bastante pulverizada, composta por vários fundos de investimento, sendo o Blackrock o principal controlador com 6,2\% das ações. O Blackrock por sua vez é composto por um conjunto grande de sócios, cujos mais importantes são o PNC Financial, Wellington Management, Barclays, o governo da Noruega e o JP Morgan, entre outros tantos. Ao longo deste período, através do aporte de capital dado pelos fundos ao seu processo de crescimento, a UnitedHealth tornou-se a maior empresa do setor nos Estados Unidos e uma das maiores do mundo, com receita operacional próxima de US\$ 100 bilhões de dólares e com ativos totais de cerca de US\$ 80 bilhões em 2012.

Embora mais recente, a Hercules Holding Inc., proprietária da HCA, apresenta uma história semelhante. A companhia passou a ocupar a posição de segundo maior conglomerado de saúde nos Estados Unidos a partir de um rápido processo de crescimento via fusões e aquisições financiadas por fundos de investimento. A holding foi organizada a partir de 2006 com o fechamento do capital e incorporação dos ativos da HCA Inc. pela Hercules Holding, que passou a controlar os ativos da área de serviços de saúde. A holding é controlada por um consórcios grande de fundos de investimento, cujos principais acionistas são Bain Capital Investors e Kohlberg Kravis Roberts \& Co. (KKR), entre outros fundos sediados nos Estados Unidos e Reino Unido principalmente.

Após a incorporação da HCA pela Hercules Holding, a companhia adquiriu uma série de hospitais, clínicas e laboratórios na Austrália, Canadá, Suécia, Finlândia e Reino Unido. Este processo foi acompanhado pela reestruturação dos negócios da holding nos Estados Unidos com a venda de um conjunto vasto de hospitais de médio porte e a concentração dos negócios em redes de grandes hospitais. A companhia também focou sua estratégia na compra de empresas de planos de saúde, sobretudo no Reino Unido. Recentemente o fundo Bain Capital, controlador da holding, anunciou a compra do Grupo NotreDame Intermédica, sediado em São Paulo, com negócios na área de seguros saúde, centros clínicos, hospitais e pronto-socorros.

A companhia reúne atualmente cerca de 2.400 subsidiárias, espalhadas por mais de dez países, atuando em seguros de saúde, análise clínica, assistência médico-hospitalar e logística médica. No ano de 2013, as subsidiárias da companhia reunidas apresentaram uma receita operacional de cerca de US\$ 18 bilhões, com ativos totais na ordem de US\$ 63 bilhões, compondo um dos maiores conglomerados de serviços de saúde dos Estados Unidos. Deve-se ressaltar também que os principais controladores da holding, Bain Capital 
e KKR, participam do controle de outra série de empresas independentes da holding que atuam no segmento de serviços de saúde nos Estados Unidos e em outros países.

O Community Health Systems pode ser considerado o terceiro grande conglomerado formado nos Estados Unidos a partir dos fundos financeiros. A companhia é controlada pelos fundos Glenview Capital Management, Baron Capital e Blackrock, com $10,6 \%, 6,15 \%$ e 5,6\% respectivamente, acompanhados por um vasto número de pequenos acionistas. O fundo Blackrock também consta entre os principais acionistas da UnitedHealth e da Kindred Healthcare. Em 2012, a Community Health encerrou o ano com receita operacional de US\$ 13 bilhões aproximadamente e um total de ativos de US\$16,6 bilhões.

A Community Health também apresentou crescimento baseado na capitalização de sua estratégia de compra de outras grandes empresas por fundos de investimento. Este processo permitiu que a empresa triplicasse de tamanho entre os anos de 2006 e 2008. A partir 2007, a Community Health adquiriu a Triad Hospitals por cerca de US\$ 7 bilhões, a Tenet Healthcare por US\$ 7,5 bilhões, e recentemente, a Health Management por aproximadamente US\$ 8 bilhões. A rodada de compras da Community Health, somada às grandes aquisições dos outros três grandes conglomerados com base de operação nos Estados Unidos, fornecem bem uma ideia da proporção que a concentração do mercado norte-americano vem tomando a partir da onda de fusões e aquisições da segunda metade da década de 2000.

O maior conglomerado do setor fora dos Estados Unidos, o grupo alemão Fresenius, controlador da Fresenius Medical Care, reúne ativos na área de saúde na ordem de US\$ 112 bilhões, com uma receita operacional em 2012 de aproximadamente US\$ 72 bilhões. O grupo tem como principal acionista a empresa familiar Else Kroener - Fresenius, porém contando com um grande número de pequenos acionistas entre os quais destacam-se o Skandinaviskan Enskilda Banken (SEB) e a Allianz, entre outros fundos de investimento de diferentes nacionalidades.

Seguindo a mesma lógica o grupo iniciou nos anos 2000 uma série de aquisições de grande porte. Em 2001, a Fresenius adquiriu Wittgensteiner Kliniken e, em 2005, o grupo adquiriu a Helios, terceira maior administradora de hospitais da Alemanha. Neste período, a Frenesius ainda adquiriu a Renal Care Group, a APP Pharmaceuticals, a National Medical, a Liberty Dialysis Holding, a American Access Care Holdings e a Everest Healthcare, entre outras empresas que serviram de base para a ampliação dos negócios do grupo nos Estados Unidos. Nos países em desenvolvimento, o grupo expandiu sua presença na Índia - com a compra da Dabur Pharma e da Goa Formulations, ambas no setor de fármacos, e a Mafatlal Industries, produtora de equipamentos - com atuação na China, Taiwan, Singapura, México, Colômbia e Argentina.

O grupo também aumentou significativamente sua presença em vários países europeus. De modo geral, o grupo Frenesius aproveitou seu negócio original ligado aos tratamentos de diálise para diversificar suas atividades em um conjunto vasto de negócios. Além das atividades de serviços médicos, o grupo verticalizou suas atividades para equipamentos médicos em geral, química fina, fármacos - incluindo de uso veterinário - e complementos nutricionais, neste caso inclusive, demonstrando recentemente interesse na aquisição desta divisão de negócios da Danone. O grupo ainda atua na América Latina em 
serviços de tecnologia da informação para a área de saúde em uma joint venture com a NetCare.

A NetCare é um conglomerado no setor de saúde de capital sul-africano e inglês, atuando majoritariamente na área de assistência médico-hospitalar, análise clínica e seguros de saúde. A receita operacional do grupo como um todo para 2012 foi de aproximadamente US\$ 7 bilhões e os ativos totais contabilizaram cerca de US\$ 16 bilhões. A Netcare é controlada pelo fundo de investimentos Coronation Fund Managers com atuação principalmente no continente africano, tendo porém uma vasta carteira de negócios que inclui participações relevantes na indústria automotiva, moda, indústria extrativa, telecomunicações e outras atividades em diversos países. O fundo, além do capital sulafricano, conta com um grupo vasto de capitais de diferentes nacionalidades, mas principalmente advindos dos Estados Unidos e Grã-Bretanha.

A NetCare concentrou sua estratégia em aquisições no Reino Unido e África do Sul, salvos alguns casos isolados de compra de ativos nos Estados Unidos e Portugal. Entre estas aquisições, possivelmente a de maior importância foi a aquisição do General Healthcare Group no Reino Unido em 2006. A aquisição envolveu um consórcio de fundos de investimento, incluindo o Apax Partners, fundo controlador da Capio AB. A General Helthcare Group iniciou recentemente um processo de recapitalização, através da venda de ativos não considerados estratégicos e de emissões primárias de ações. A partir da capitalização da General Healthcare, a NetCare adquiriu indiretamente um conjunto de hospitais da Nuffield - outro grande grupo inglês de serviços de saúde - e vem transformando a General Healthcare na base de expansão do grupo Netcare no Reino Unido.

Outra empresa do hemisfério sul de crescimento acelerado foi a australiana Ramsay Health Care. A empresa acelerou seu processo de crescimento via aquisições, iniciando a expansão a partir de 2000, com as aquisições de quatro grandes empresas do setor na Austrália - a Affinity Health, a Australian Hospital Care, Alpha Healthcare e a Benchmark Healthcare - enquanto recebia o aporte de capital de alguns fundos importantes como a Barclays, do Reino Unido, e a FMR e Fidelity International, ambas dos Estados Unidos. O grupo obteve em 2012 uma receita operacional de US\$ 4 bilhões aproximadamente e reunia ativos no valor de cerca de US\$ 3,6 bilhões. A importância do processo de capitalização para o crescimento da empresa fica claro quando observado o desempenho da empresa na última década. Desde 2004 a receita operacional da companhia cresceu acima de $600 \%$ enquanto os ativos totais cresceram de US\$ 475 milhões para cerca de US\$ 3,7 bilhões no mesmo período.

Após a rodada de concentração no mercado australiano a Ramsay Health Care expandiu seus negócios para o Reino Unido, França, Indonésia e Malásia. No Reino Unido, além da compra de algumas redes de hospitais de menor porte, a companhia adquiriu os negócios da Capio UK em 2007, subsidiária do grupo sueco Capio AB. Depois de algumas aquisições na França, em 2010 a companhia comprou 57\% do capital da Proclif, empresa que passou a reunir os ativos da Ramsay no mercado francês, passando a chamar-se Ramsay Santé. Em 2103, a Ramsay estabeleceu uma joint venture com o conglomerado malaio Sime Derby para a exploração de serviços de saúde no sudeste asiático - a Ramsay Sime Derby Healthcare. 
A Kindred Healthcare, ao contrário das demais empresas líderes, permaneceu concentrada em sua principal área de negócios, assistência médico-hospitalares, e com a estratégia focada em seu mercado doméstico, os Estados Unidos, ao longo de toda a década. A exceção fica por conta da diversificação para a distribuição e revenda de fármacos, através da Kindred Pharmacies, e para a abertura de capital da Kindred Biosciences, recém-fundada empresa de fármacos para uso veterinário do grupo.

A Kindred é controlada por um conjunto de fundos de investimentos, cada um com pequena porcentagem de ações na companhia. O principal acionista é novamente o fundo Blackrock, seguido pelos fundos Wellington Management e Dimensional Fund. Para o ano de 2012, a receita operacional alcançou a cifra de US\$ 4,9 bilhões, com o valor dos ativos totais de aproximadamente US\$ 4,2 bilhões. A companhia concentrou sua política de compra em empresas nos Estados Unidos que atuassem em seu core business, entre as quais as principais aquisições foram a RehabCare por cerca de US\$ 1,3 bilhão, a Triumph Healthcare, por US\$ 500 milhões, e a Commonwealth Communities Holdings, por US\$ 125 milhões.

De modo geral, a Kindred focou seu crescimento na aquisição de hospitais, clínicas de reabilitação e de cuidado com idosos e em empresas de enfermagem especializada. A atuação dos fundos financeiros, assim como nos outros casos, serviu para impulsionar a rápida concentração destes mercados através da capitalização de estratégias de aquisição. Embora a Kindred não tenha iniciado seu processo de internacionalização, a concentração dos mercados de serviços de saúde nos Estados Unidos e o porte já assumido pela empresa após a aquisição de empresas concorrentes faz com sua internacionalização seja bem provável nos próximos anos, seguindo o movimento já iniciado pelos demais conglomerados na área de saúde.

A RHK é a segunda maior empresa de serviços de saúde no mercado alemão, embora tenha controle familiar, a companhia tem um alto percentual de ações em free float e a participação de alguns acionistas importantes como o fundo JP Morgan e o grupo Fresenius, com 5\% do capital, formando uma participação acionária cruzada entre duas grandes empresas concorrentes no mercado alemão. A receita operacional da RHK foi em 2012 de cerca de US\$ 4 bilhões e os ativos totais alcançaram a cifra de US\$ 4,2 bilhões. Assim como a Kindred Health Care, a RHK concentrou seus negócios no mercado doméstico e focado na construção, operação e administração hospitalar, crescendo através da aquisição de empresas na mesma área e aumento gradual de sua escala de operação.

Entre os anos de 2006 e 2009, a RHK iniciou um processo de aquisições, cujas principais compras foram a Amper Kliniken AG, a Wesermarsch-Klinik e o St. PetriHospitals. O processo de crescimento do grupo foi em grande parte financiado através de um aporte de cerca de US\$ 1 bilhão através da emissão de títulos subscrito por um consórcio de bancos liderados pelo Commerzbank AG e o Morgan Stanley. A capitalização do grupo permitiu aumentar seu capital em torno de $50 \%$ e garantir o aumento da participação da RHK no disputado mercado alemão. Assim como a Kindred Health Care, entre as grandes empresas a RHK é uma das poucas que manteve seu crescimento contido ao mercado doméstico.

A Capio AB é um conglomerado sediado na Suécia, controlado pelos fundos Apax Partners e Nordic Capitals, que possuem cerca de 200 empresas nas áreas de finanças, 
empreendimentos imobiliários, tecnologia em tratamentos médicos e serviços de saúde nesta atuando principalmente em assistência médico-hospitalar e planos de saúde. Para o ano de 2012, a receita do grupo foi de aproximadamente US\$ 1,6 bilhão de dólares, com um total de ativos de cerca de US\$ 2 bilhões. Atuando em quase toda Europa, embora controlando suas operações a partir das sedes na Suécia, Noruega, França, Alemanha e Reino Unido. A internacionalização do grupo, ainda que contida no continente europeu foi bem ampla, com negócios relevantes na Espanha, Suíça, França, Dinamarca, Noruega, Alemanha, Reino Unido e Itália, para citar apenas as operações de maior porte.

Entre as empresas líderes, a Capio é a com maior grau de internacionalização, com cerca de $50 \%$ da receita gerada fora do mercado doméstico. A companhia investiu na aquisição do controle de algumas grandes empresas, como a suíça Unilabs, a UK Healthcare e a Community Hospitals - ambas no Reino Unido - o Grupo Sanitario, na Espanha, e o Tonkin Group, na França. A Capio posteriormente vendeu alguns ativos importantes, cujo principal foi a venda da Capio UK para a Ramsay Health Care por cerca de US\$ 316 milhões. Entretanto, a internacionalização do grupo ainda está em fase de expansão, tanto em relação aos negócios da Capio $A B$, quanto em relação aos negócios na área de saúde do fundo Apax Partners, principal controlador do grupo.

De modo geral, a associação entre fundos financeiros e empresas de serviços de saúde contribui para a rápida concentração e internacionalização dos mercados de saúde dos países de alta renda. No caso dos Estados Unidos, em que o mercado de saúde combina renda per capita alta com grande participação dos gastos privados em saúde - ao contrário dos países europeus com grandes sistemas públicos de saúde centralizados - o nível de concentração alcançou níveis bastante elevados, com a formação de alguns dos maiores conglomerados do setor.

O processo também teve em comum algumas características em relação à conduta dos fundos financeiros. A entrada dos fundos coincidiu com um movimento de recompra de ações e fechamento de capital de algumas unidades intermediárias dos grandes grupos. Este movimento resultou na composição de algumas grandes holdings de serviços de saúde comandadas por consórcios bem vastos de fundos financeiros, geralmente com participação acionária pulverizada e com participação de fundos de diferentes nacionalidades. A consolidação deste processo vem reduzindo cada vez mais o número de hospitais, clínicas e laboratórios independentes das grandes redes, que por seu turno, vêm se tornando cada vez mais internacionalizadas.

O processo descrito revela uma característica importante do processo de financeirização, geralmente negligenciado. Em relação à ótica de curto prazo associada à participação dos investidores institucionais no controle das empresas não-financeiras, a resposta à necessidade de redução de custos e aumento dos níveis de rentabilidade vem sendo dada a partir da ampliação das escalas e integração internacional das operações, acirrando o processo de centralização do capital em nível global e gerando processos de formação de conglomerados internacionais de grande porte. 


\section{Gráfico 4 - Participação Majoritária Consolidada dos Fundos Financeiros nas 1000 Maiores Aquisições - 1997-2015 ${ }^{4}$}

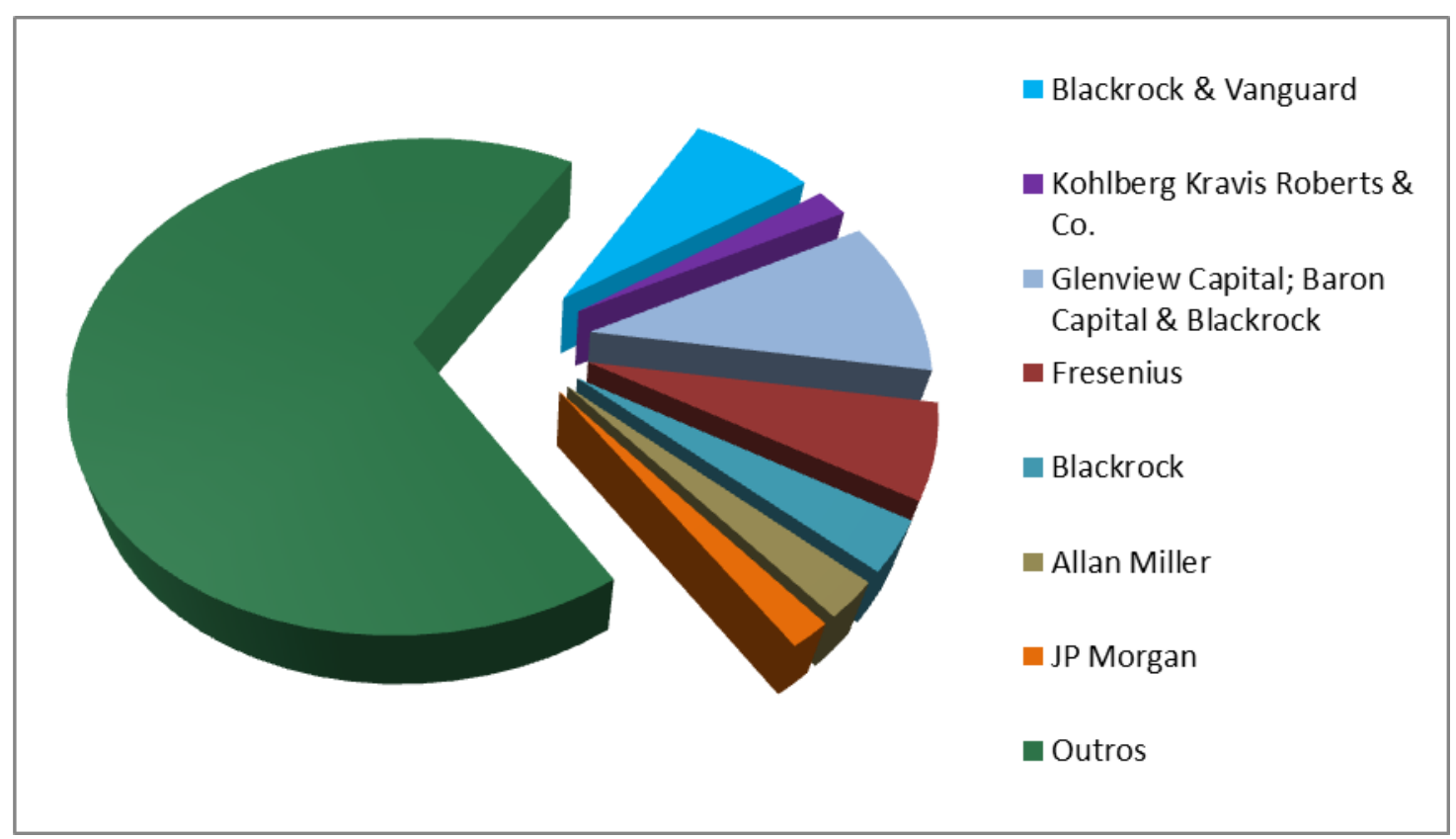

Fonte: Elaboração NEIT/IE/UNICAMP a partir de dados de Zephir/BVD.

No gráfico acima é possível verificar a concentração das aquisições sob o controle dos fundos financeiros. Chama atenção a concentração de aproximadamente um quarto das operações em um número reduzidos de fundos - direta e indiretamente - o que demonstra como o setor de saúde vem sendo um segmento importante nas estratégias de valorização de certos fundos. A composição de sociedades entre fundos financeiros de grande porte para a viabilização das estratégias de crescimento demonstra também a preocupação em incrementar rapidamente as operações de aquisição de empresas de grande porte, apontando mais para a existência de estratégias estáveis de concentração e formação de conglomerados do que para ganhos especulativos de capital no curto prazo.

Alguns grandes fundos como o Apax Partners, o Blackrock Inc., o Bain Capitals e o Vanguard, ao longo da década aumentaram significativamente suas participações em diversos empreendimentos na área de saúde, espalhados em diversos continentes. Embora alguns sejam concentrados em grandes empresas do setor, a participação destes fundos é bem mais vasta que o volume de ativos reunidos nas empresas líderes. Os fundos, até mesmo pela sua liquidez no mercado de capitais e pelo alcance global de suas operações, vêm dando a tônica do processo de concentração em escala internacional. A concentração nos mercados centrais já atingiu um nível elevado, restando apenas algumas possíveis aquisições de grande porte, o que leva a crer que o processo de internacionalização deverá se voltar sobretudo para os mercados emergentes.

\footnotetext{
${ }^{4}$ Os dados são referentes à consolidação dos ativos a partir da aquisição integral ou superior a 50\% do capital de uma empresa adquirida, levando em consideração os fundos com a maior participação acionária na empresa compradora.
} 
Outra característica relevante dos mercados desenvolvidos é que a divisão de trabalho entre Estado e setor privado restringe a margem de atuação do setor privado, dado a abrangência dos sistemas públicos de saúde, limitando assim também o número de atividades em que a diversificação é possível. Neste sentido, a formação de um vasto mercado de renda per capita mais elevada nos países em desenvolvimento, com sistemas públicos de saúde precários ou de pouca abrangência, fornece um mercado em potencial para o crescimento da participação dos fundos financeiros, em mercados com taxas de expansão mais elevadas que os seus mercados domésticos originais.

\section{3 - TRANSFORMAÇÕES RECENTES NO SETOR DE SERVIÇOS DE SAÚDE PRIVADOS NO BRASIL.}

O setor brasileiro de provisão de serviços de saúde, medido a partir dos dispêndios totais com hospitais (públicos e privados), clínicas, serviços médicos, medicamentos e equipamentos médicos, totalizou cerca de US\$ 240 bilhões em 2012. A taxa de crescimento verificada entre 2008 e 2012 foi de 12,5\%, comparada com uma taxa de 4,6\% observada nos Estados Unidos e 4,8\% no Canadá. (MarketLine, 2012).

O Sístema Único de Saúde (SUS) é responsável pelo provimento geral de serviços de saúde universal. Nos últimos anos, porém, tem ocorrido uma movimentação importante no segmento de saúde suplementar, com alguns sinais de que o cenário de maior concorrência internacional, abordado na seção anterior, tem se verificado de maneira mais efetiva no Brasil, em especial no período pós-crise internacional. Os dados de crescimento apresentados no parágrafo anterior permitem perceber o diferencial em termos de taxa de crescimento entre o Brasil e Estados Unidos e Canadá, o que justifica esse interesse. Esta seção busca justamente detalhar o sentido geral dessas transformações, descrevendo as linhas gerais de mudanças observadas.

Na tabela 2, estão as 25 maiores empresas associadas aos serviços de saúde em 2012, listadas entre as empresas da publicação Valor 1000, que reúne informações financeiras das 1000 maiores empresas brasileiras.

Através destes dados é possível perceber como, apesar da estrutura pulverizada em termos de número de empresas, existem algumas grandes empresas atuando nos diferentes segmentos, com volume de faturamento bastante elevado. O grupo Amil aparece como maior empresa do setor, com receita líquida de R\$ 10,4 bilhões em 2012. Em seguida aparecem duas empresas de Seguro Saúde (Bradesco e Sul América) e somente na quarta posição um grupo com atividade hospitalar (Rede Dor). Em termos de diagnóstico laboratorial, a Diagnósticos da América (DASA) é a maior empresa e aparece na oitava posição entre as 25 maiores.

Tabela 2 - Receita Líquida das 25 maiores empresas do setor de serviços de saúde.

\section{Em R\$ milhões.}

Empresa Segmento Receita Líquida




\begin{tabular}{|c|c|c|}
\hline AmilPar & Plano de Saude & $10.464,00$ \\
\hline Bradesco Saúde & Seguro Saúde & $7.743,80$ \\
\hline Sul América Seguro Saúde & Seguro Saúde & $5.431,20$ \\
\hline Rede Dor & Serviços Médicos & $3.122,10$ \\
\hline Unimed Rio & Plano de Saude & $2.773,40$ \\
\hline Hospitais São Paulo & Serviços Médicos & $2.484,60$ \\
\hline NotreDame Intermédica & Plano de Saude & $2.349,20$ \\
\hline Diagnósticos da América & Serviços Médicos & $2.264,10$ \\
\hline Unimed Paulistana & Plano de Saude & $2.232,30$ \\
\hline Unimed Belo Horizonte & Plano de Saude & $2.144,40$ \\
\hline Golden Cross & Plano de Saude & $1.874,10$ \\
\hline Central Unimed Nacional & Plano de Saude & $1.631,80$ \\
\hline Sul América Saúde & Seguro Saúde & $1.536,00$ \\
\hline Hospital Albert Einstein & Serviços Médicos & $1.528,90$ \\
\hline Fleury Medicina e Saúde & Serviços Médicos & $1.501,80$ \\
\hline Hospital Santa Catarina & Serviços Médicos & $1.322,10$ \\
\hline \multicolumn{3}{|l|}{ Hospital e Maternidade São } \\
\hline Camilo & Serviços Médicos & $1.316,50$ \\
\hline Santa Casa de São Paulo & Serviços Médicos & $1.117,60$ \\
\hline Unimed Curitiba & Plano de Saude & $1.113,80$ \\
\hline Unimed Porto Alegre & Plano de Saude & $1.095,30$ \\
\hline Unimed Campinas & Plano de Saude & $1.026,20$ \\
\hline Esho & Serviços Médicos & $1.020,00$ \\
\hline Porto Seguro Saúde & Seguro Saúde & 957,90 \\
\hline Odontoprev & Plano de Saude & 956,80 \\
\hline Hospital Santa Marcelina & Serviços Médicos & 904,40 \\
\hline
\end{tabular}

Fonte: Valor 1.000.

As informações analisadas nesta seção procuram destacar o movimento recente de concentração pelo qual vem passando o setor. Este processo vem ocorrendo desde o início dos anos 2000, porém tem se intensificado nos últimos anos em razão de dois movimentos simultâneos e muitas vezes interconectados. O primeiro deles está associado à busca dos grandes grupos internacionais por novos polos de expansão nos países em desenvolvimento, dado o forte movimento de consolidação já ocorrido nos países centrais, assim como à busca de mercados com maiores perspectivas de crescimento da demanda. $\mathrm{O}$ 
segundo está relacionado ao crescente interesse dos fundos de investimento, tanto de capital nacional quanto de capital estrangeiro, por oportunidades de investimento no mercado de serviços de saúde no Brasil.

O processo de concentração no setor de Planos de Saúde foi marcado pela mesma busca de economias de escala, observada no cenário internacional, juntamente com a necessidade de atender à regulamentação com a criação da ANS em 2000. Além disso, é válido ressaltar que o movimento de concentração foi acompanhado por mudanças no sentido da verticalização das atividades. Se nos anos 80 e 90 o movimento de verticalização foi marcado pelos hospitais ofertando seus próprios planos de saúde, mais recentemente as operadoras têm buscado ampliar o número de hospitais próprios. Além de reduzir custos com o atendimento direto aos beneficiários, em especial os custos com internações, a existência de rede própria também aumenta o poder de negociação com outros fornecedores.

A Amil, por exemplo, vinha, mesmo antes de ser adquirida pela UnitedHealth, realizando um processo intenso de compra, tanto de outras operadoras como de hospitais. Entre estas aquisições podem ser destacadas a Blue Life em 2007, a Ampla e a Casa de Saúde Santa Lúcia em 2008, a Medial em 2009, a Saúde Excelsior em 2010 e o Samaritano e Pasteur do Rio de Janeiro em 2011. Em 2013, a Amil tinha em sua rede própria 22 hospitais e 50 clínicas médicas, além de mais dois hospitais em construção.

A entrada de operadores internacionais no mercado brasileiro pode acentuar ainda mais o movimento de consolidação do setor, assim como reforçar a estratégia de verticalização. Do ponto de vista da atração de investidores estrangeiros, o fato que mais chamou a atenção foi a entrada da americana UnitedHealth no Brasil, ao comprar a Amil. O negócio foi fechado após um longo período de negociações. De acordo com informações da imprensa especializada, a venda de $90 \%$ do seu capital à UnitedHealth foi avaliada em R\$ 9,8 bilhões. Além do valor da transação, a operação marcou a entrada da maior operadora de planos de saúde do mundo no mercado brasileiro. Como mostrado na seção 3, em 2012 o faturamento da United Health atingiu cerca de US\$ 100 bilhões (frente a um faturamento de cerca de US\$ 5,1 bilhões da Amil).

De acordo com reportagem do Valor (7/08/2013), após a aquisição pela UnitedHealth, a Amil negociava a compra de outros hospitais, não só como forma de ampliar sua rede própria, consolidando a estratégia de verticalização, mas também como forma de expandir sua abrangência em regiões onde a operadora ainda tem presença pequena.

No mesmo sentido, também pode ser registrado o interesse de outras empresas, como a Colsanitas, pertencente à holding colombiana Organizacion Sanitas Internacional (OSI). Em 2011, a Colsanitas comprou 45\% da operadora brasileira Universal Saúde e recentemente anunciou a intenção de aumentar a participação para $80 \%$. Segundo notícias veiculadas na imprensa, o objetivo do grupo no mercado brasileiro é comprar outras operadoras de planos de saúde e montar uma rede própria de hospitais e clínicas, aos moldes do que possui na Colômbia.

Boatos sobre a compra da Golden Cross pelo fundo norteamericano KKR também circularam na imprensa em 2012, embora efetivamente não tenha se concretizado nenhuma operação. 
Mais recentemente (março de 2014), a terceira maior operadora de planos de saúde do Brasil teve uma das unidades do grupo adquirida por um grupo estrangeiro. $\mathrm{O}$ grupo NotreDrame Intermédica vendeu a Intermédica para o fundo estadunidense de private equity Bain Company. Embora o valor oficial não tenha sido revelado, a imprensa noticiou o valor da operação em US\$ 2 bilhões.

Aliás, a participação de fundos de investimento no setor de saúde é outra novidade, que tem contribuído para acelerar as transformações do setor de serviços de saúde privados no Brasil. Além da entrada da Bain Company adquirindo a Intermédica, podem ser citados vários outros exemplos de participação dos fundos de private equity no setor de saúde.

Um dos principais exemplos é a capitalização da empresa de medicina diagnóstica Hermes Pardini, pelo fundo Gávea. A partir da venda de 30\% de seu capital para o Gávea em 2011, a Hermes Pardini iniciou um processo de aquisições, onde se destaca a compra de $70 \%$ do capital da Diagnóstika, laboratório paulista especializado em exames de alta complexidade, com receita estimada de R\$ 27 milhões. Além disso, anunciou a compra de 80\% do Padrão, laboratório de Goiás com receita de R\$ 50 milhões. Em 2012, fechou três aquisições: Digimagem (SP), Progenética (RJ) e o mineiro Biocod. (Valor, 27/04/2013)

O Gávea também está em negociação para a aquisição do controle do segundo maior laborátorio do País, o Fleury. A Core Participações, formado pelos médicos que detêm o controle do Fleury, anunciou que está estudando a proposta para a venda de 41,2\% das ações que dão controle majoritário à Core. O valor estimado do bloco de controle é de R\$ 1,5 bilhões, porém o valor total da operação deve ser maior em razão da necessidade de estender a oferta aos minoritários, inclusive o Bradesco Saúde, que detém atualmente 16,4\% do capital do Fleury (Valor, 12/03/2014).

Já o Fundo Pátria decidiu montar uma empresa no setor de exames de imagen, a Alliar, em 2011. Anteriormente, o Pátria tinha participação na DASA, porém desfez-se de sua participação em 2009. Nos últimos 2 anos, a Alliar realizou 11 aquisições de outros laboratórios de exames de imagem. As aquisições foram feitas em grande parte através da troca de ações das empresas adquiridas por ações da Alliar.

Na contramão dos movimentos anteriores, o grupo DASA registrou recentemente o aumento da participação do empresário Edson Bueno e sua ex-mulher Dulce Pugliesi, antigos controladores da Amil, no controle da empresa. Com a aquisição de 48,35\% por R\$ 2,3 bilhões, a participação dos novos controladores saltou para 71,94\%. Fundos como Tarpon, Petros e Oppenheimar, tiveram, assim, sua participação diminuída no capital total da empresa (Valor Econômico, 12/03/2014).

No caso dos hospitais, o movimento de consolidação é relativamente mais lento em relação aos demais segmentos do setor de serviços. A existência de um grande número de hospitais sem fins lucrativos, aliada à restrição legal de participação de capital estrangeiro, tem reduzido os processos de fusão e aquisição. No entanto, cabe destacar que o maior grupo privado no setor, o Rede D’Or, tem seguido uma estratégia mais agressiva de aquisições. De acordo com reportagem do jornal Valor de 03/04/2013, o grupo realizou 17 aquisições nos 5 anos anteriores, praticamente dobrando o faturamento entre 2010 e 2012. Nesse processo, foi importante a parceria do BTG Pactual, que, além de ter participação 
minoritária, auxiliou o grupo hospitalar no lançamento de debêntures para financiar a expansão e também tem assessorado o grupo no processo de aquisições.

Essa intensa movimentação no setor de serviços de saúde pode também ser observado através da análise dos números referentes a fusões e aquisições no Brasil. As informações sobre os processos de fusões e aquisições no Brasil foram coletadas junto à base de dados Zephir-BVD.

No caso específico dos setores selecionados, as informações coletadas mostram uma tendência de aumento no número de operações, que vão atingir o volume máximo em 2008, com posterior redução no período pós-crise, porém mantendo um número de operações importantes. Em termos de valores, é possível verificar como estes atingem patamares mais elevados a partir de 2008, chegando ao valor máximo em 2012.

Gráfico 5 Número e valor das operações de fusões e aquisições envolvendo empresas do setor de serviços de saúde no Brasil.

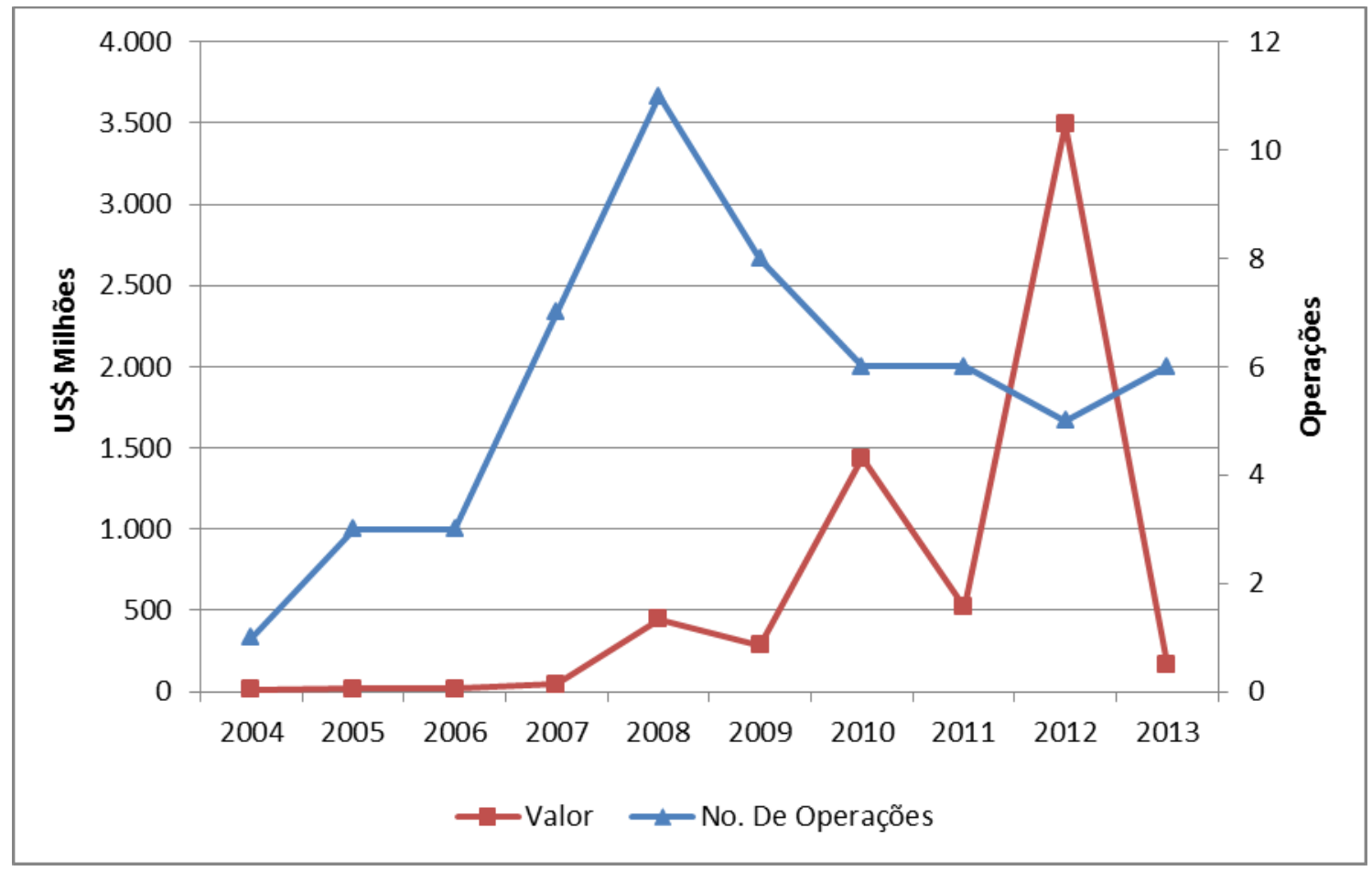

Fonte: Elaboração NEIT/UNICAMP a partir de Zephyr/BVD

Considerando o total de operações acumuladas entre 2004 e 2013, dos 58 registros encontrados, 23 não tinham registros de valor. A maior parte das operações se concentrou na faixa dos US\$ 10 a US\$ 50 milhões. Duas operações tiveram registro acima de US\$ 1 bilhão e 3 na faixa entre US\$ 200 milhões e US\$ 1 bilhão. 
Tabela 3 - Operações de Fusões e Aquisições no Brasil no setor de serviços de saúde, por valor de operação. 2004 a 2013.

\begin{tabular}{lr}
\hline Acima de US\$ 1 bilhão & 2 \\
Entre US\$ 200 milhões e US\$ 1 & 3 \\
bilhão & 6 \\
Entre US\$ 50 e US\$ 200 milhões & 15 \\
Entre US\$ 10 e US\$ 50 milhões & 9 \\
Ate US\$ 10 milhões & 23 \\
sem valor & 58 \\
\hline Total
\end{tabular}

Fonte: Elaboração NEIT/UNICAMP a partir de Zephyr/BVD

A grande maioria das operações ainda diz respeito a fusões e aquisições que envolvem empresas nacionais (tabela 4). Porém, a participação de estrangeiros vem se tornando mais comum. Além disso, também vale destacar que, como mostra a entrada da UnitedHealth e da Bain Company (ainda não captada na tabela 4, pois foi anunciada em 2014), em geral a entrada das estrangeiras acontece em grandes operações, que têm impactos relevantes sobre a estrutura do setor.

Tabela 4 - Operações de Fusões e Aquisições no Brasil no setor de serviços de Saúde, por origem da adquirente. 2004 a 2013.

\begin{tabular}{lcc}
\hline Origem & Operações & $\begin{array}{c}\text { Valor (US\$ } \\
\text { milhões) }\end{array}$ \\
\hline Nacionais & 53 & $3.084,0$ \\
\hline Estrangeiros & 5 & $3.346,6$ \\
\hline França (2011) & 1 & n.d \\
Estados Unidos & & \\
(2012) & 1 & $3.207,9$ \\
Canada (2012) & 1 & 120,7
\end{tabular}




\begin{tabular}{lcc} 
Espanha (2013) & 1 & n.d \\
Colômbia (2013) & 1 & 18,0 \\
\hline & 58 & $6.430,6$
\end{tabular}

Fonte: Elaboração NEIT/UNICAMP a partir de Zephyr/BVD

Finalmente, as operações captadas por empresa adquirente mostram uma concentração relativamente importante das operações nas grandes empresas do setor. Interessante notar também que a comparação entre o número de operações registrado na base de dados e as informações colhidas junto à imprensa especializada permite intuir que as operações registradas pela Zephyr/BVD estão subestimadas, registrando apenas as maiores operações do setor. Por exemplo, a Rede D’Or aparece com apenas 3 operações na tabela 5, enquanto as informações de outras fontes apontam 17 aquisições.

Tabela 5 - Operações de Fusões e Aquisições no Brasil no setor de serviços de Saúde, por principais empresas. 2004 a 2013.

\begin{tabular}{lcc}
\hline Adquirente & Operações & $\begin{array}{c}\text { Valor (US\$ } \\
\text { milhões) }\end{array}$ \\
\hline Dasa & 13 & 1.218 .953 \\
Fleury & 7 & 442.689 \\
Amil/Amil & 4 & 501.616 \\
participações & 4 & 38.759 \\
Odontoprev & 3 & 432.776 \\
Grupo Bradesco & 3 & 163.360 \\
Rede D'Or & 3 & n.d \\
Hermes Pardini & 3 & n.d \\
Sacmil & 3 & 33.628 \\
Sul América & 2 & n.d \\
Qualicorp & & $2.831 .780,1$ \\
\hline
\end{tabular}

Fonte: Elaboração NEIT/UNICAMP a partir de Zephyr/BVD

De qualquer maneira, os dados analisados nesta seção apontam para um processo intenso de alterações na estrutura do setor de serviços de saúde. O movimento de consolidação no setor de Planos de Saúde foi bastante intenso nos últimos anos, embora 
ainda exista um conjunto de operadores menores que podem ser alvo de novos movimentos no futuro. Também no setor de serviços de laboratório e diagnóstico, o processo de concentração tem sido bastante intenso. A capitalização por fundos de investimentos nacionais e internacionais tem sido um potente alavancador do movimento de consolidação.

O segmento menos sujeito ao processo, embora tenha passado também por um movimento de fusões e aquisições, é justamente o setor hospitalar. Este setor tem se deparado, por um lado, com a busca por redução de custos e a estratégia de verticalização dos planos de saúde. Por outro, tem enfrentado elevação de custos importantes, em especial no caso do avanço em tecnologias complexas5, como forma de atingir segmentos de renda mais elevada. Essa situação tem levado vários hospitais menores a uma situação financeira delicada, o que tem afetado inclusive o número de leitos colocados à disposição pelo setor privado.

Aparentemente, o movimento de consolidação no setor de saúde ainda pode ter desdobramentos importantes no futuro, com implicações também importantes sobre as agencias reguladoras e sobre os diversos níveis da política pública voltada para este setor.

\section{CONSIDERAÇÕES FINAIS}

Estas considerações finais têm o objetivo apenas de levantar de maneira preliminar algumas questões relativas às consequências do movimento descrito nas seções anteriores. Longe de ser um levantamento exaustivo, trata-se apenas de um primeiro esforço de análise, que deve necessariamente ser complementado através do diálogo com outros estudos sobre o setor.

Em primeiro lugar deve-se destacar o desafio colocado para as agências reguladoras. Em relação ao CADE (Conselho Administrativo de Defesa da Concorrência) os vários processos de concentração no setor têm sido objeto de crescente atenção do Conselho, com a preocupação de reduzir o poder de mercado resultante das fusões e aquisições.

O desafio maior, no entanto, cabe à ANS. A busca por escala e melhores condições de custo e rentabilidade move o processo de concentração do setor, impulsionado inclusive por movimentos de capitalização advindos do processo de internacionalização de empresas e fundos financeiros internacionais em busca de novos espaços de valorização. Se por um lado esse movimento pode permitir também investimentos em expansão e melhora de eficiência produtiva, por outro pode também significar práticas de elevação de preços, discriminação de preços, excluindo clientes de renda mais baixa do acesso a procedimentos mais sofisticados, racionalização excessiva, inclusive em termos de mão-deobra, reduzindo a qualidade do atendimento.

A inclusão de novos atores, como grandes grupos estrangeiros e fundos financeiros, reforça essa tensão na medida em que aumenta o poder econômico dos agentes atuantes no setor e, ao mesmo tempo, induz a transferência de mecanismos de gestão que

\footnotetext{
${ }^{5}$ O Robô cirúrgico Da Vinci, por exemplo, tem custo estimado entre US\$ 1,5 e 3 milhões, somente da máquina, sem contar custos de treinamento e manutenção.
} 
pressionam por maiores retornos e busca de eficiência operacional. O aumento do porte e da capacidade dos grupos privados com certeza exigirá uma capacidade de resposta maior da ANS, assim como maior necessidade de se antepor aos interesses puramente privados para poder gerar consequência positiva para a população atendida.

Do ponto de vista dos hospitais, embora seja vedado o controle direto por empresas estrangeiras, indiretamente a aquisição das operadoras de planos de saúde por agentes estrangeiros cria uma situação de concorrência onde essa influência necessariamente será sentida. A concentração no setor de planos de saúde e a busca por redução de custos significam, do ponto de vista dos hospitais, uma dificuldade para aumentar a receita. Essa pressão pode levar, por um lado, à replicação do movimento de consolidação no próprio setor de hospitais, como mostra a estratégia do Grupo D’Or. Por outro, deve reforçar a pressão sobre o restante da cadeia de fornecimento, fato que pode resultar em piora na qualidade, assim como na dificuldade de expansão do número de leitos. Em uma situação onde a pressão pelo aumento de leitos deve continuar aumentando, esse fator pode pressionar ainda mais a necessidade de investimentos públicos na expansão de sua rede de atendimento hospitalar.

Finalmente, cabe destacar que o movimento de internacionalização e concentração do setor privado de serviços de saúde também representa desafios para a articulação que está sendo organizada para o desenvolvimento do complexo industrial da saúde. Atores que atuam com uma lógica global tendem a reforçar laços com fornecedores globais de produtos, equipamentos, insumos e serviços tecnológicos, forçando um timing que pode ir de encontro ao esforço de construir capacidades produtivas e tecnológicas locais.

\section{Bibliografia}

JENSEN, M. O eclipse do grupo empresarial de capital aberto. In Montgomery, C. e Porter, M.(orgs.) Estratégia. Rio de Janeiro: Campus. 1998:

CROTTY, J. The effects of increased product market competition and changes in financial markets on the performance of Nonfinancial Corporations in the neoliberal era. PERI Working paper, n. 44. 2002.

LAZONICK, W. e O’SULLIVAN, M. Maximizin shareholder value: a new ideology for corporate governance, Economy and Society, vol.29 n.1. 2000

MARKET LINE. Healthcare Providers in Brazil. Market Line Industry Profile. 2013.

UNCTAD. World Investment Report. The shift toward services. Genebra: Unctad. 2004

ARROW, K. J. Uncertainty and the welfare economics of medical care. The American

Economic Review, Pittsburgh, v. 53, n. 5, p.941-970, 1963.

CHESNAIS, F. A Mundialização do Capital. Sao Paulo: Xama, 1996. 336 p. 
CONILL, E. M. Sistemas comparados de saúde. In: CAMPOS, G. W. de S. et al. Tratado de saúde coletiva. São Paulo: Hucitec; Rio de Janeiro: Fiocruz, 2008. p. 563-613.

EPSTEIN, G. (ed.) Financialization and theWorld Economy, Cheltenham, UK, Edward Elgar. 2005.

CRESWELL, J.; ABELSON, Reed. New Laws and Rising Costs Create a Surge of Supersizing Hospitals. The New York Time. New York, 12 ago. 2013. Disponível em: $<$ http://www.nytimes.com/2013/08/13/business/bigger-hospitals-may-lead-to-bigger-billsfor-patients.html?pagewanted=all\&_r=0 > . Acesso em: 01 jul. 2014.

IUNES, R. F. Demanda e demanda em saúde. In: PIOLA, S. F.; VIANNA, S. M. (Org.). Economia da Saúde: Conceitos e Contribuição para a Gestão da Saúde. Brasilia: Ipea, 1995. p. 99-123.

PETERSON, J. New Laws and Rising Costs Create a Surge of Supersizing Hospitals. New York Times. 12/08/2013.

SARTI, F. et al. Indústria Mundial: mudanças e tendências recentes. In: SARTI, F. et al (Org.). Perspectivas do investimento na indústria. Rio de Janeiro: Synergia; Campinas: UNICAMP, 2010. p. 1-42.

UNITED NATIONS CONFERENCE ON TRADE ANDE DEVELOPMENT . World Investment Report 2004: The Shift Towards Services. Geneva: Unctad, 2004. 162 p

VAN DER ZWAN, N. Making Sense of Financialization. Socio-Economic Review (2014) 12, 99-129.

Valor 1000. Vários números. 